\title{
Utilization of PCI After Fibrinolysis
}

\author{
Peter McKavanagh, George Zawadowski, \\ and Warren J. Cantor
}

\subsection{Introduction}

It is estimated that there are 1.5 million hospitalizations with acute coronary syndromes (ACS) per year in the United States, with 30-45\% being a ST-segment elevation myocardial infarction (STEMI) presentation $[1,2]$. STEMI occurs due to an acute occlusion of an infarct-related artery (IRA) that can cause irreversible ischemia-induced myocardial necrosis within 20-60 min of onset. Untreated STEMI patients have higher mortality and poor clinical outcomes compared to those who receive a reperfusion strategy [3-10]. The mainstay of STEMI management is rapid intervention aimed at relieving the IRA thrombotic obstruction and thus reducing infarct size, preserving left ventricular function, and decreasing morbidity and mortality. In the 1980s, fibrinolysis became the standard means to achieve reperfusion. Subsequently, a number of randomized trials and meta-analyses showed that primary PCI (PPCI), when performed rapidly, was associated with improved clinical outcomes compared to fibrinolytic therapy [11-18]. However, the mortality benefit of primary PCI is reduced with treatment delays, with no benefit observed when the difference between time of fibrinolysis and time of PCI exceeds $115 \mathrm{~min}$ $[19,20]$. Current guidelines recommend the use of fibrinolytic therapy when the time from first medical contact to PCI is anticipated to be greater than $120 \mathrm{~min}$ $[17,18]$. Despite these recommendations, data from the US National Cardiovascular Data Registry showed that only $51 \%$ of STEMI patients transferred for primary PCI

P. McKavanagh

Ulster Hospital, Belfast, UK

G. Zawadowski

Interventional Cardiology, St. Michael's Hospital, University of Toronto,

Toronto, ON, Canada

W. J. Cantor $(\bowtie)$

Southlake Regional Health Centre, University of Toronto, Toronto, ON, Canada

e-mail: cantorw@rogers.com 
achieved the recommended first door-to-balloon time of $<120$ min [21]. Similar European data show that $65 \%$ of transferred patients had a delay of $>120$ min, which was associated with increased mortality [22].

Many strategies have been developed to increase the number of patients who can undergo timely primary PCI, including prehospital identification of STEMI and establishment of networks that allow ambulances to bypass the closest hospital and take patients directly to PCI facilities [23-34]. Nevertheless, there will always be a cohort of patients who are too far from PCI centers, and fibrinolytic therapy remains the treatment of choice for these patients $[35,36]$. Transporting patients to a PCI center for routine early PCI after fibrinolysis, the so-called pharmacoinvasive strategy, has been shown to reduce the risks of reinfarction and recurrent ischemia with no increase in major bleeding. Within the literature, there exist examples of successful implementation of a combined primary PCI and pharmacoinvasive strategies depending on patient distance from facilities [37], with regional systems proposed [38]. This chapter addresses the evidence for PCI after fibrinolytic therapy, illustrating how and when it should be used.

\subsection{Fibrinolytic Therapy}

The use of fibrinolytic therapy in STEMI is long established, with pioneering work in 1976 by Chazov et al. showing benefit [39]. Prior to the development of fibrinolytic therapy, treatment of STEMI was limited to analgesia, antiplatelets, anticoagulants, and blood pressure management. The use of fibrinolytic therapy became the standard practice after the pivotal randomized clinical trials Gruppo Italiano per lo Studio della Streptochinasi nell'Infarto Miocardico (GISSI) and Second International Study of Infarct Survival (ISIS-2) [40, 41]. These two studies used intravenous streptokinase (SK) showing a mortality benefit when compared to placebo, especially in combination with aspirin. Based on these studies, SK became standard treatment for STEMI. However there remained concerns about bleeding and limited efficacy, leading to the development of fibrin-specific fibrinolytic agents. These included tissue plasminogen activator (alteplase) [42, 43], recombinant plasminogen activator (reteplase) [44, 45], and tenecteplase [46]. Overall there have been over 40 trials comparing different fibrinolytic regimens. A recent meta-analysis indicated that the lowest mortality and bleeding rates were seen with the use of reteplase, alteplase, and tenecteplase in combination with parenteral anticoagulant therapy [47].

The main advantage of fibrinolytic therapy is the ease of administration, which includes the ability to be given in small rural hospitals and in the prehospital setting. It is most effective when administered early (especially within the first $2 \mathrm{~h}$ of symptom onset). To help with appropriate administration, there are time recommendations for each step (Table 5.1). There are however substantial limitations of fibrinolytic therapy, and it is essential that its use is appropriate (Figs. 5.1 and 5.2). Firstly, there is risk of major bleed, including intracranial bleeding, with SK having the highest risk [47]. Secondly, only $40-50 \%$ of all patients treated with fibrinolytic 
Table 5.1 Time targets for fibrinolytic therapy

\begin{tabular}{l|l}
\hline Intervals & Time targets \\
\hline Maximum time from FMC to 1st ECG and STEMI diagnosis & $\leq 10 \mathrm{~min}$ \\
\hline Maximum time from STEMI diagnosis to fibrinolytic therapy & $\leq 10 \mathrm{~min}$ \\
\hline Time from fibrinolytic therapy to assessment of reperfusion efficacy & $60-90 \mathrm{~min}$ \\
\hline Time from fibrinolytic therapy to angiography (if fibrinolysis is successful) & $2-24 \mathrm{~h}$ \\
\hline
\end{tabular}

FMC first medical contact. Adapted from 2017 ESC STEMI Guidelines [17]

\section{Indications:}

- Chest pain or other ischemic symptoms $<12$ hours duration

- Persistent ST elevation in $\geq 2$ contiguous leads

$$
\begin{array}{ll}
- & \geq 2 \mathrm{~mm} \text { in anterior leads }(\geq 1.5 \mathrm{~mm} \text { in women) } \\
\text { - } & \geq 1 \mathrm{~mm} \text { in inferior leads } \\
\text { - } & \text { Absence of LBBB, LVH or other STEMI mimics }
\end{array}
$$

\section{Absolute Contraindications:}

- Any prior intracranial hemorrhage

- Intracranial vascular or malignant lesion (AVM, tumour)

- Ischemic stroke within 3 months

- Sustained Hypertension: SBP > 180 or DBP > $110 \mathrm{~mm} \mathrm{Hg}$

- Active bleeding or bleeding diathesis (not incl menses)

- Significant closed head or facial trauma within 3 months

\section{Relative Contraindications:}

- Cardiogenic Shock

- Traumatic or prolonged CPR

- Major surgery within past 3 weeks

- Internal bleeding within past 4 weeks

- Active peptic ulcer disease

- Non-compressible vascular puncture

- Pregnancy

- Current use of anticoagulants

Fig. 5.1 Indications and contraindications for fibrinolytic therapy

1. Use Fibrin-specific Agent (Accelerated tPA, Reteplase, Tenecteplase)

2. Administer ASA $160 \mathrm{mg}$ chewed, Clopidogrel $300 \mathrm{mg}$ (75 mg if patient $>75$ years of age)

3. Administer parenteral anticoagulant

a. UFH $60 \mathrm{U} / \mathrm{kg}$ bolus ( $\max 4000 \mathrm{U}$ ) then $12 \mathrm{U} / \mathrm{kg}$ per hour ( $\max 1000 \mathrm{U} / \mathrm{hr}$ )

b. Enoxaparin $30 \mathrm{mg}$ IV plus $1 \mathrm{mg} / \mathrm{kg} \mathrm{sc}$ (Avoid for elderly patients or renal insufficiency)

c. Fondaparinux IV bolus followed by $2.5 \mathrm{mg}$ sc dose 24 hours later

4. Transfer patient to $\mathrm{PCl}$ center immediately after fibrinolytic therapy for pharmacoinvasive protocol if possible

5. If pharmacoinvasive strategy not possible, transfer to $\mathrm{PCl}$ hospital for hemodynamic instability or evidence of failed reperfusion (persistent chest pain or ST elevation) at 60-90 minutes after fibrinolysis

Fig. 5.2 Fibrinolysis checklist 
therapy achieve normal TIMI (Thrombolysis in Myocardial Infarction) grade 3 flow, with this figure even lower in elderly patients or those with cardiogenic shock [48-51]. Even patients with TIMI grade 3 flow may have evidence of failed myocardial perfusion [52]. Noninvasive identification of successful reperfusion after fibrinolytic therapy is challenging, with limited positive and negative predictive values for resolution of chest pain and ST-segment elevation. Furthermore, approximately $5 \%$ of patients will reinfarct after initial successful reperfusion [53].

\subsection{PCl-Based Approaches}

Given these limitations of fibrinolytic therapy, and the time dependency of primary PCI, it has been questioned whether combining fibrinolytic therapy and PCI could be the ideal treatment strategy, particularly for patients who cannot undergo timely primary PCI. This combined strategy would minimize treatment delays using rapid administration of fibrinolytic therapy but also achieve complete and sustained reperfusion using PCI. The use of PCI after fibrinolytic therapy can be classified based on the timing and indications for PCI (Table 5.2).

\subsubsection{Rescue PCI}

Patients who have persistent chest pain and ST elevation after fibrinolytic therapy require urgent cardiac catheterization and rescue PCI to restore flow to the occluded infarct-related artery. Rescue PCI is indicated in the case of suspected failed fibrinolysis (i.e., ST-segment resolution $<50 \%$ within 60-90 min of fibrinolytic administration) or hemodynamic instability [18]. The landmark rescue PCI trials were Rescue Angioplasty versus Conservative Treatment or Repeat Thrombolysis (REACT) and the Middlesbrough Early Revascularization to Limit Infarction (MERLIN) [54, 55]. REACT compared rescue PCI, medical management, and

Table 5.2 Reperfusion strategies combining fibrinolytic therapy and PCI

\begin{tabular}{l|l}
\hline Strategy & Definition \\
\hline Rescue PCI & Emergent PCI performed for failed reperfusion after fibrinolytic therapy \\
\hline Facilitated PCI & $\begin{array}{l}\text { Administration of fibrinolytic therapy (and/or GP IIb/IIIa inhibitors) prior } \\
\text { to emergent PCI to bridge PCI-related time delays (PCI within } 2 \mathrm{~h} \text { of } \\
\text { fibrinolytic therapy) }\end{array}$ \\
\hline $\begin{array}{l}\text { Pharmacoinvasive } \\
\text { strategy }\end{array}$ & $\begin{array}{l}\text { Administration of fibrinolytic therapy followed by immediate transfer to } \\
\text { a PCI center; emergent PCI for patients with evidence of failed } \\
\text { reperfusion, hemodynamic instability, or reinfarction; and PCI within } \\
\text { 24 h of fibrinolytic therapy for patients who are stable with successful } \\
\text { reperfusion }\end{array}$ \\
\hline
\end{tabular}


repeat fibrinolytic therapy for patients with clinical evidence of failed reperfusion after fibrinolysis. Rescue PCI was associated with a reduction in reinfarction, with no mortality difference between treatments. The trial was terminated prematurely raising concerns about the true benefit. MERLIN compared rescue PCI and conservative therapy but did not show significant reduction of the primary endpoint, allcause mortality. In addition, in both trials, patients who underwent rescue PCI had increased bleeding. Meta-analyses have been performed to help guide practice. Patel et al. included five trials and found a 36\% decrease in the risk of death with rescue PCI (RR 0.64, 95\% confidence interval $0.41-1.00, p=0.048)$ and a marginally significant $28 \%$ decrease in the risk of heart failure (RR $0.72,95 \%$ confidence interval $0.51-1.01, p=0.06$ ) [56]. Wijeysundera et al. analyzed eight trials and found that rescue PCI was not associated with a significant reduction in mortality but was associated with significant reductions in heart failure (RR $0.73,95 \% \mathrm{CI}$ 0.54-1.00) and reinfarction (RR $0.58,95 \%$ CI 0.35-0.97) when compared with conservative treatment [57]. Rescue PCI was also associated with an increased risk of stroke (RR 4.98, 95\% CI 1.10-22.5) and minor bleeding. Another meta-analysis by Testa et al. had similar findings. Rescue PCI was associated with a $70 \%$ reduction in the risk of reinfarction [OR $0.32(0.14-0.74), p=0.008$ ], with a number needed to treat of 17. On balance rescue PCI is superior to conservative therapy for patients with failed reperfusion after fibrinolytic therapy and has a Class I indication in the guidelines $[17,18]$.

\subsubsection{Facilitated PCI}

Initial attempts to routinely combine pharmacological reperfusion therapy and PCI focused on administering fibrinolytic agents and/or glycoprotein IIb/IIIa inhibitors to patients being transferred for immediate PCI to help bridge the treatment delay. This strategy was termed "facilitated PCI" and was assessed in two large randomized trials.

The Assessment of the Safety and Efficacy of a New Treatment Strategy with Percutaneous Coronary Intervention (ASSENT-4 PCI) randomized patients to either PPCI $(n=838)$ or facilitated PCI using full-dose tenecteplase $(n=829)$ [58]. The median time from tenecteplase to first balloon inflation was $104 \mathrm{~min}$. The primary endpoint (death or congestive heart failure or shock within 90 days) was found in $19 \%$ of patients assigned to facilitated PCI vs. $13 \%$ of those randomized to PPCI (relative risk 1.39, 95\% CI 1.11-1.74, $p=0.0045)$. During hospital stay, significantly more strokes $(1.8 \%$ vs. $0, p<0.0001)$ were reported in patients assigned to facilitated rather than standard PPCI. There were also more ischemic cardiac complications, such as reinfarction $(6 \%$ vs. $4 \%, p=0.0279)$ or repeat target vessel revascularization ( $7 \%$ vs. $3 \%, p=0.0041)$ within 90 days. 
The Facilitated Intervention with Enhanced Reperfusion Speed to Stop Events (FINESSE) study randomized 2452 patients to undergo facilitated PCI using a combination of abciximab plus half-dose reteplase, facilitated PCI using abciximab alone, or primary PCI [59]. The primary endpoint was the composite of death from all causes, ventricular fibrillation occurring more than $48 \mathrm{~h}$ after randomization, cardiogenic shock, and congestive heart failure during the first 90 days after randomization. The primary endpoint occurred in $9.8,10.5$, and $10.7 \%$ of the patients in the combination-facilitated PCI group, abciximab-facilitated PCI group, and primary PCI group, respectively ( $p=0.55)$; 90-day mortality rates were 5.2, 5.5, and $4.5 \%$, respectively $(p=0.49)$.

A meta-analysis comparing facilitated and primary percutaneous coronary intervention was published by Keeley et al.[60]. In this they identified 17 trials of patients with STEMI assigned to facilitated $(n=2237)$ or primary $(n=2267)$ PCI. The facilitated PCI group had higher rates of death (5\% vs. $3 \% ; 1.38,1.01-1.87)$, nonfatal reinfarction rates ( $3 \%$ vs. $2 \% ; 1.71,1.16-2.51)$, and urgent target vessel revascularization rates $(4 \%$ vs. $1 \% ; 2.39,1.23-4.66)$. Facilitated PCI was associated with higher rates of major bleeding than PPCI (7\% vs. 5\%; 1.51, 1.10-2.08). Hemorrhagic stroke was also higher in fibrinolytic therapy facilitated regimens compared with primary PCI (hemorrhagic stroke $0.7 \%$ vs. $0.1 \%, p=0.0014$; total stroke $1.1 \%$ vs. $0.3 \%, p=0.0008$ ). The overall conclusion was that facilitated PCI offers no benefit over PPCI and should be avoided.

There are several limitations of the facilitated PCI trials and meta-analysis. Firstly, FINESSE was not included in the meta-analysis, and thus more than half of the patients in the analysis came from the ASSENT-4 trial. Of the 17 trials, 9 used only glycoprotein IIb/IIIa inhibitors and no fibrinolytic, and of the remaining 8 fibrinolytic trials (except ASSENT-4), most of them were small and used balloon angioplasty without coronary stents. Another important limitation to these trials is the absence of up-front clopidogrel loading at the time of fibrinolysis. Fibrinolytic therapy increases platelet activation and aggregation, and without clopidogrel loading, PCI performed early after fibrinolysis may be predisposed toward thrombotic complications [61].

Most patients enrolled in the facilitated PCI studies underwent PCI within 120 min of fibrinolysis. Secondary analyses of the ASSENT-4 and FINESSE study suggested that there may be a subgroup of patients (such as high-risk patients who presented early to non-PCI hospitals) that could benefit from facilitated PCI $[62,63]$. However there is no large dataset to support this, and facilitated PCI is not currently recommended in guidelines.

\subsubsection{Pharmacoinvasive}

The pharmacoinvasive strategy applies to STEMI patients who are treated with fibrinolysis at a non-PCI center. It involves transferring patients to a PCI center right after fibrinolysis (without waiting to see if reperfusion is successful), followed by routine early PCI. For those patients who successfully reperfuse with 
fibrinolytic therapy, early PCI prevents recurrent ischemia and reinfarction. In the case of failed reperfusion or clinical instability, the patient undergoes emergent PCI on arrival to the PCI center. Figure 5.3 is a checklist for the use of a pharmacoinvasive strategy.

A number of studies have compared routine early PCI after fibrinolysis with an ischemia-driven conservative strategy or delayed PCI [64-68]. The initial studies

Fig. 5.3 Flow diagram for pharmacoinvasive strategy

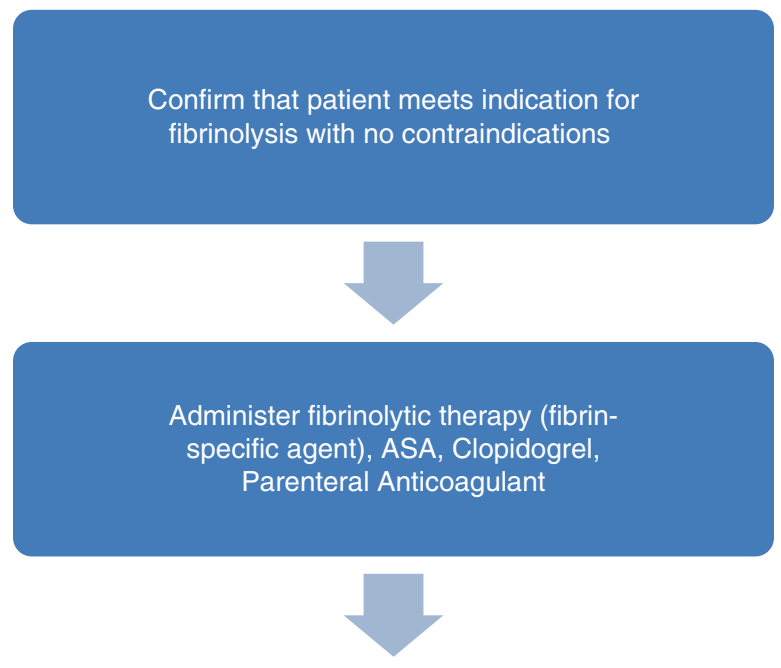

Transfer patient to $\mathrm{PCl}$ center as soon as possible after fibrinolytic therapy (ideally within first hour, not waiting to assess reperfusion)

On arrival to $\mathrm{PCl}$ center, if patient has ongoing chest pain, persistent ST elevation

or hemodynamic instability, perform emergent coronary angiography \& PCI

If patient arrives to $\mathrm{PCl}$ center stable and painfree with clinical reperfusion, perform coronary angiography \& $\mathrm{PCl}$ within 24 hours 
were done prior to the use of coronary stents and antiplatelet agents that help maintain infarct artery patency and showed increased rates of emergency bypass surgery and higher mortality when PCI was performed routinely within $24 \mathrm{~h}$ of fibrinolysis [69]. Studies that were performed using contemporary PCI techniques (including coronary stenting) and pharmacotherapy have shown improved outcomes with routine early PCI after fibrinolysis [70].

The largest such randomized trial, TRANSFER-AMI (Trial of Routine Angioplasty and Stenting After Fibrinolysis to Enhance Reperfusion in Acute Myocardial Infarction), randomized 1059 high-risk patients who received fibrinolytic therapy to either usual care (including rescue PCI for failed fibrinolytic therapy) or urgent transfer to a PCI-capable hospital for a routine early PCI within $6 \mathrm{~h}$ after fibrinolytic therapy [71]. The primary endpoint - a composite of death, reinfarction, recurrent ischemia, new or worsening heart failure, or cardiogenic shock within 30 days-was reached in $17.2 \%$ of patients in the usual care group and $11.0 \%$ of patients assigned to an early invasive strategy (RR $0.64,95 \%$ CI $0.47-$ $0.87, p=0.004)$. A meta-analysis of seven contemporary trials comparing a pharmacoinvasive strategy to ischemia-driven (or delayed) PCI after fibrinolytic therapy (Figure 5.1) demonstrated a significant reduction in death or MI at 6 months to 1 year in the pharmacoinvasive group, with no difference in stroke or major bleeding (Fig. 5.4) [72].

Real-world data from a prospective registry involving a rural population served by a large regional health network demonstrated the safety and efficacy of a pharmacoinvasive strategy. Two thousand six hundred twenty-four consecutive patients presenting with STEMI to a non-PCI-capable hospital, more than 60 miles from the nearest PCI center, received aspirin, clopidogrel, unfractionated heparin, and half-dose fibrinolysis and were transferred for PCI. When outcomes were compared to STEMI patients presenting directly to PCI centers for primary PCI, there were no significant differences in 30-day mortality (5.5\% vs. $5.6 \%, p=0.94)$, stroke $(1.1 \%$ vs. $1.3 \%, P=0.66)$, major bleeding ( $1.5 \%$ vs. $1.8 \%, p=0.65)$, or reinfarction $(1.2 \%$ vs. $2.5 \%, p=0.088)$ despite a longer doorto-balloon time [73]. An analysis of the FAST-MI also showed no difference in

Death-Peinfarction, 6-12 months

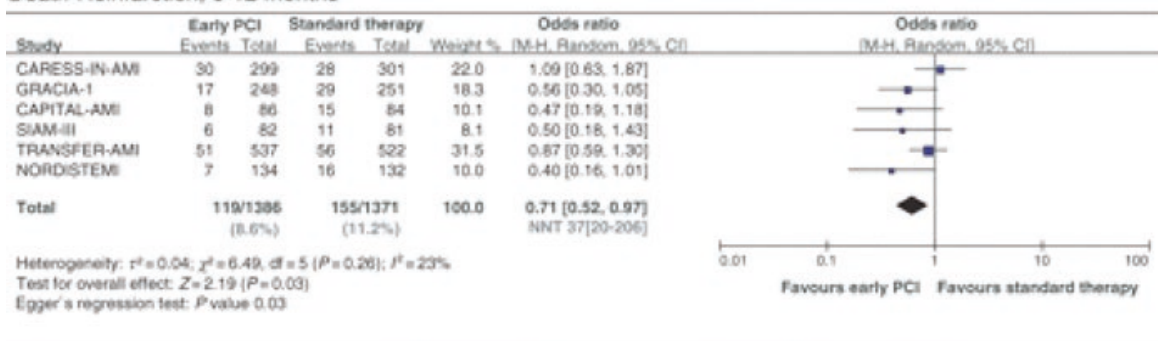

Fig. 5.4 Clinical endpoints at 6-12 months when comparing early routine percutaneous coronary intervention after fibrinolysis vs. standard therapy in ST-segment elevation myocardial infarction. Taken from a meta-analysis by Borgia et al. [72] 
risk-adjusted mortality at 1 year with primary PCI compared to a pharmacoinvasive strategy [74].

The STREAM trial was an international, multicenter randomized trial comparing a pharmacoinvasive strategy to primary PCI in 1892 STEMI patients presenting within $3 \mathrm{~h}$ from symptom onset but who were unable to undergo PPCI in less than $1 \mathrm{~h}$ after first medical contact [75]. The primary outcome was a composite of death, reinfarction, shock, or congestive heart failure. There was no significant difference in the composite primary endpoint between the two groups, $12.4 \%$ in the fibrinolysis group versus $14.3 \%$ in the primary PCI group ( $p=0.21,95 \%$ CI $0.68-1.09)$. There was a higher rate of intracranial hemorrhage in the fibrinolysis group $(1.0 \%$ vs. $0.2 \%, p=0.004)$. However, after a protocol amendment to decrease the fibrinolytic dose by half in patients $\geq 75$ years of age, there was no longer any significant difference in rates of intracranial hemorrhage between groups $(0.5 \%$ vs. $0.3 \%$, $p=0.45)$. It is important to note that almost one third of patients experienced a PPCI delay of less than $1 \mathrm{~h}$ and the average time from first medical contact to balloon inflation was $117 \mathrm{~min}$. As such, the results of the STREAM trial may not be applicable to patients who cannot undergo primary PCI within $120 \mathrm{~min}$ of first medical contact.

Based on the results of contemporary pharmacoinvasive trials, current guidelines recommend transfer to a PCI-capable hospital after fibrinolysis "even when hemodynamically stable and with clinical evidence of successful reperfusion," to undergo coronary angiography and revascularization within $24 \mathrm{~h}$ after fibrinolysis (Class IIa, Level of Evidence B) [17, 18].

\subsection{Antiplatelet Therapy as Adjunct to Fibrinolysis}

Current guidelines recommend adjunctive antiplatelet therapy in the setting of fibrinolysis in the form of aspirin 162-325 mg as well as clopidogrel $300 \mathrm{mg}$ (for patients $<75$ years of age) or $75 \mathrm{mg}$ (for patients $>75$ years of age) (Class I, Level of Evidence A) [17, 18]. The largest trial studying the use of dual antiplatelet therapy was the CLARITY-TIMI 28 trial [53], published in 2005. In CLARITY, the authors randomized 3491 patients presenting within $12 \mathrm{~h}$ of onset of STEMI who were planned for fibrinolysis with adjunctive anticoagulant and aspirin to either clopidogrel (300 mg loading dose followed by $75 \mathrm{mg}$ daily) or placebo. The primary endpoint was a composite of occluded IRA on angiography, death prior to angiography, or recurrent MI prior to angiography. For patients who did not undergo angiography, the primary endpoint was death or recurrent MI by day 8 . The primary safety endpoint was TIMI major bleeding. The primary endpoint occurred in $21.7 \%$ of the placebo group versus $15.0 \%$ in the clopidogrel group (OR 0.64, 95\% CI 0.53-0.76, $p<0.001$ ), an absolute reduction of $6.7 \%$. There was no difference in the rate of TIMI major bleeding.

In the modern era of primary PCI, two novel oral P2Y12 inhibitors have been studied for use in acute coronary syndrome in conjunction with aspirin as part of a dual antiplatelet strategy, namely, prasugrel and ticagrelor [76, 77]. The safety 
of combining these more potent P2Y12 inhibitors with fibrinolytic therapy is not known. The TREAT trial randomized 3800 STEMI patients treated with fibrinolytic therapy to ticagrelor or clopidogrel. The primary endpoint is major bleeding. Enrollment was recently completed, and the results of this trial are anticipated in 2018.

More recently, cangrelor, an intravenous, fast-acting, and rapidly reversible P2Y12 inhibitor, has become available for use in the setting of primary PCI, but has not been studied as part of a pharmacoinvasive or fibrinolytic strategy [78].

\subsection{Optimal Timing of PCl After Fibrinolytic Therapy}

While the current guidelines recommend coronary angiography within $24 \mathrm{~h}$ after fibrinolysis as part of a pharmacoinvasive strategy, they discourage performing angiography less than 2-3 h after fibrinolysis, based in part on the adverse outcomes seen in the facilitated PCI trials. However, there remains uncertainty regarding the optimal timing of angiography after fibrinolysis. In TRANSFER-AMI, the median time from randomization to first balloon inflation was $3.2 \mathrm{~h}$, with an interquartile range of 2.5-4.2 h [71]. A meta-analysis evaluating the timing of PCI after fibrinolysis found higher rates of recurrent ischemia and a trend to higher reinfarction when angiography was performed $>4$ h after fibrinolysis [79].

\section{Conclusions}

Fibrinolysis remains a mainstay of STEMI treatment throughout the world and is the initial reperfusion strategy of choice when primary PCI cannot be performed with a first medical contact to balloon time less than 120 min. Fibrin-specific fibrinolytic agents should be used, combined with clopidogrel and parenteral anticoagulant therapy. Patients should be transferred to PCI centers right after receiving fibrinolytic therapy and undergo coronary angiography and revascularization within $24 \mathrm{~h}$. Regional STEMI networks should provide both primary PCI and pharmacoinvasive strategy, based on anticipated first medical contact to balloon times.

\section{References}

1. Mozaffarian D, Benjamin EJ, Go AS, et al. Heart disease and stroke statistics-2015 update: a report from the American Heart Association. Circulation. 2015;131:e29-e322.

2. Hong MK. Recent advances in the treatment of ST-segment elevation myocardial infarction. Scientifica. 2012;2012:1-13.

3. Bugiardini R, Badimon L, ISACS-TC Investigators and Coordinators. The International Survey of Acute Coronary Syndromes in Transitional Countries (ISACS-TC): 2010-2015. Int J Cardiol. 2016;217(Suppl:S1-6). https://doi.org/10.1016/j.ijcard.2016.06.219. Epub 2016 Jun 28 
4. Roe MT, Messenger JC, Weintraub WS, et al. Treatments, trends, and outcomes of acute myocardial infarction and percutaneous coronary intervention. J Am Coll Cardiol. 2010;56:254-63.

5. Kadakia MB, Desai NR, Alexander KP, et al. Use of anticoagulant agents and risk of bleeding among patients admitted with myocardial infarction: a report from the NCDR ACTION RegistryGWTG (National Cardiovascular Data Registry Acute Coronary Treatment and Intervention Outcomes Network Registry — Get With the Guidelines). J Am Coll Cardiol Intv. 2010;3:1166-77.

6. Farshid A, Brieger D, Hyun K, Hammett C, Ellis C, Rankin J, Lefkovits J, Chew D, French J. Characteristics and clinical course of STEMI patients who received no reperfusion in the Australia and New Zealand SNAPSHOT ACS registry. Heart Lung Circ. 2016;25(2):132-9.

7. Sim DS, Jeong MH, Ahn Y, Kim YJ, Chae SC, Hong TJ, Seong IW, Chae JK, Kim CJ, Cho MC, Rha SW, Bae JH, Seung KB, Park SJ, Korea Acute Myocardial Infarction Registry (KAMIR) Investigators. Pharmacoinvasive strategy versus primary percutaneous coronary intervention in patients with ST-segment-elevation myocardial infarction: a propensity scorematched analysis. Circ Cardiovasc Interv. 2016;9(9). pii: e003508

8. Zubaid M, Rashed W, Alsheikh-Ali AA, Garadah T, Alrawahi N, Ridha M, Akbar M, Alenezi F, Alhamdan R, Almahmeed W, Ouda H, Al-Mulla A, Baslaib F, Shehab A, Alnuaimi A, Amin H. Disparity in ST-segment elevation myocardial infarction practices and outcomes in Arabian gulf countries (Gulf COAST Registry). Heart Views. 2017;18(2):41-6.

9. Xavier D, Pais P, Devereaux PJ, et al. Treatment and outcomes of acute coronary syndromes in India (CREATE): a prospective analysis of registry data. Lancet. 2008;371:1435-42.

10. Mohanan PP, Mathew R, Harikrishnan S, Krishnan MN, Zachariah G, Joseph J, Eapen K, Abraham M, Menon J, Thomas M, Jacob S, Huffman MD, Prabhakaran D, Kerala ACS Registry Investigators. Presentation, management, and outcomes of 25748 acute coronary syndrome admissions in Kerala, India: results from the Kerala ACS registry. Eur Heart J. 2013;34(2):121-9.

11. Rosselló X, Huo Y, Pocock S, de Werf FV, Chin CT, Danchin N, Lee SW, Medina J, Vega A, Bueno H. Global geographical variations in ST-segment elevation myocardial infarction management and post-discharge mortality. Int J Cardiol. 2017;245:27-34.

12. Zijlstra F, de Boer MJ, Hoorntje JC, Reiffers S, Reiber JH, Suryapranata H. A comparison of immediate coronary angioplasty with intravenous streptokinase in acute myocardial infarction. N Engl J Med. 1993;328:680-4.

13. Grines CL, Browne KF, Marco J, Rothbaum D, Stone GW, O'Keefe J, Overlie P, Donohue B, Chelliah N, Timmis GC. A comparison of immediate angioplasty with fibrinolytic therapy for acute myocardial infarction. The primary angioplasty in myocardial infarction study group. $\mathrm{N}$ Engl J Med. 1993;328:673-9.

14. Gibbons RJ, Holmes DR, Reeder GS, Bailey KR, Hopfenspirger MR, Gersh BJ. Immediate angioplasty compared with the administration of a fibrinolytic agent followed by conservative treatment for myocardial infarction. The Mayo Coronary Care Unit and Catheterization Laboratory Groups. N Engl J Med. 1993;328:685-91.

15. Keeley EC, Boura JA, Grines CL. Primary angioplasty versus intravenous fibrinolytic therapy for acute myocardial infarction: a quantitative review of 23 randomised trials. Lancet. 2003;361:13-20.

16. Dalby M, Bouzamondo A, Lechat P, Montalescot G. Transfer for primary angioplasty versus immediate thrombolysis in acute myocardial infarction. A meta-analysis. Circulation. 2003;108:1809-14.

17. Ibanez B, James S, Agewall S, Antunes MJ, Bucciarelli-Ducci C, Bueno H, Caforio ALP, Crea F, Goudevenos JA, Halvorsen S, Hindricks G, Kastrati A, Lenzen MJ, Prescott E, Roffi M, Valgimigli M, Varenhorst C, Vranckx P, Widimský P, ESC Scientific Document Group 2017. ESC guidelines for the management of acute myocardial infarction in patients presenting with ST-segment elevation: the task force for the management of acute myocardial infarction in 
patients presenting with ST-segment elevation of the European Society of Cardiology (ESC). Eur Heart J. 2017. https://doi.org/10.1093/eurheartj/ehx393. [Epub ahead of print]

18. O'Gara PT, Kushner FG, Ascheim DD, et al. 2013ACCF/AHA guideline for the management of ST-elevation myocardial infarction: a report of the American College of Cardiology Foundation/American Heart Association Task Force on Practice Guidelines. J Am Coll Cardiol. 2013;61:e78-e140.

19. Pinto DS, Kirtane AJ, Nallamothu BK, et al. Hospital delays in reperfusion for ST-elevation myocardial infarction: implications when selecting a reperfusion strategy. Circulation. 2006;114:2019-25.

20. Chakrabarti AK, Gibson CM, Pinto DS. Optimal selection of STEMI treatment strategies in the current era: benefit of transferring STEMI patients for PCI compared with administration of onsite fibrinolytic therapy. Curr Opin Cardiol. 2012;27(6):651-4.

21. Vora AN, Holmes DN, Rokos I, et al. Fibrinolysis use among patients requiring interhospital transfer for st-segment elevation myocardial infarction care: a report from the us national cardiovascular data registry. JAMA Intern Med. 2015;175:207-15.

22. CJ T, Sørensen JT, Maeng M, Jensen LO, Tilsted HH, Trautner S, Vach W, Johnsen SP, Thuesen L, Lassen JF. System delay and mortality among patients with STEMI treated with primary percutaneous coronary intervention. JAMA. 2010;304(7):763-71.

23. Keeley EC, Grines CL. Primary percutaneous coronary intervention for every patient with ST-segment elevation myocardial infarction: what stands in the way? Ann Intern Med. 2004;141:298-304.

24. Fye WB. Introduction: the origins and implications of a growing shortage of cardiologists. J Am Coll Cardiol. 2004;44:221-32.

25. Person SD, Allison JJ, Kiefe CI, et al. Nurse staffing and mortality for Medicare patients with acute myocardial infarction. Med Care. 2004;42:4-12.

26. Goodacre S, Sampson F, Carter A, et al., Evaluation of the National Infarct Angioplasty Project: National Co-ordinating Centre for NHS Service Delivery and Organisation R\&D (NCCSDO), 2008.

27. Selmer R, Halvorsen S, Myhre KI, et al. Cost-effectiveness of primary percutaneous coronary intervention versus fibrinolytic therapy for acute myocardial infarction. Scand Cardiovasc J. 2005;39:276-85.

28. Oh EH, Imanaka Y, Evans E. Determinants of the diffusion of computed tomography and magnetic resonance imaging. Int J Technol Assess Health Care. 2005;21:73-80.

29. Labinaz M, Swabey T, Watson R, et al. Delivery of primary percutaneous coronary intervention for the management of acute ST segment elevation myocardial infarction: summary of the Cardiac Care Network of Ontario consensus report. Can J Cardiol. 2006;22:243-50.

30. Fanaroff AC, Zakroysky P, Dai D, Wojdyla D, Sherwood MC, Roe MT, Wang TY, Peterson ED, Gurm HS, Cohen MG, Messenger JC, Rao SV. Outcomes of PCI in relation to procedural characteristics and operator volumes in the United States. J Am Coll Cardiol. 2017;69(24):2913-24.

31. Boersma E. Does time matter? A pooled analysis of randomized clinical trials comparing primary percutaneous coronary intervention and in-hospital fibrinolysis in acute myocardial infarction patients. Eur Heart J. 2006;27:779-88.

32. Bradley EH, Roumanis SA, Radford MJ, et al. Achieving doorto- balloon times that meet quality guidelines: how do successful hospitals do it? J Am Coll Cardiol. 2005;46:1236-41.

33. Graff LG, Wang Y, Borkowski B, et al. Delay in the diagnosis of acute myocardial infarction: effect on quality of care and its assessment. Acad Emerg Med. 2006;13:931-8.

34. Kalla K, Christ G, Karnik R, et al. Implementation of guidelines improves the standard of care: the Viennese registry on reperfusion strategies in ST-elevation myocardial infarction (Vienna STEMI registry). Circulation. 2006;113:2398-405.

35. Sorensen JT, Terkelsen CJ, Norgaard BL, et al. Urban and rural implementation of pre-hospital diagnosis and direct referral for primary percutaneous coronary intervention in patients with acute ST-elevation myocardial infarction. Eur Heart J. 2011;32:430-6.

36. Le May MR, So DY, Dionne R, Glover CA, Froeschl MP, Wells GA, Davies RF, Sherrard HL, Maloney J, Marquis JF, O'Brien ER, Trickett J, Poirier P, Ryan SC, Ha A, Joseph PG, Labinaz 
M. A citywide protocol for primary PCI in ST-segment elevation myocardial infarction. N Engl J Med. 2008;358(3):231-40.

37. Henry TD, Sharkey SW, Burke MN, Chavez IJ, Graham KJ, Henry CR, Lips DL, Madison JD, Menssen KM, Mooney MR, Newell MC, Pedersen WR, Poulose AK, Traverse JH, Unger BT, Wang YL, Larson DM. A regional system to provide timely access to percutaneous coronary intervention for ST-elevation myocardial infarction. Circulation. 2007;116:721-8.

38. Henry TD, Gibson CM, Pinto DS. Moving toward improved care for the patient with ST-elevation myocardial infarction: a mandate for systems of care. Circ Cardiovasc Qual Outcomes. 2010;3:441-3.

39. Chazov EI, Mateeva LS, Mazaev AV. Intracoronary administration of fibrinolysin in acute myocardial infarction. Ter Arkh. 1976;48:8-19.

40. Gruppo Italiano per lo Studio della Streptochinasi nell'Infarto Miocardico (GISSI). Effectiveness of intravenous fibrinolytic treatment in acute myocardial infarction. Lancet. 1986;1:397-402.

41. ISIS-2 (Second International Study of Infarct Survival) Collaborative. Group randomised trial of intravenous streptokinase, oral aspirin, both, or neither among 17,187 cases of suspected acute myocardial infarction:ISIS-2. Lancet. 1988;2:349-60.

42. GUSTO. An international randomized trial comparing four fibrinolytic strategies for acute myocardial infarction. The GUSTO investigators. N Engl J Med. 1993;329:673-82.

43. The GUSTO Angiographic Investigators. The effects of tissue plasminogen activator, streptokinase, or both on coronary-artery patency, ventricular function, and survival after acute myocardial infarction. N Engl J Med. 1993;329:1615-22.

44. Hampton JR, Schroder R, Wilcox RG, Skene AM, Meyer-Sabellek W, Heikkila J, et al. Randomised, double-blind comparison of reteplase double-bolus administration with streptokinase in acute myocardial infarction (INJECT): trial to investigate equivalence. Lancet. 1995;346:329-36.

45. Global Use of Strategies to Open Occluded Coronary Arteries (GUSTO III) Investigators. A comparison of reteplase with alteplase for acute myocardial infarction. N Engl J Med. 1997;337(16):1118-23.

46. Van de Werf F, Adgey J, Ardissino D, Armstrong PW, Aylward P, Barbash G, et al. Singlebolus tenecteplase compared with front-loaded alteplase in acute myocardial infarction: the ASSENT-2 double-blind randomised trial. Lancet. 1999;354:716-22.

47. Jinatongthai P, Kongwatcharapong J, Foo CY, Phrommintikul A, Nathisuwan S, Thakkinstian A, Reid CM, Chaiyakunapruk N. Comparative efficacy and safety of reperfusion therapy with fibrinolytic agents in patients with ST-segment elevation myocardial infarction: a systematic review and network meta-analysis. Lancet. 2017;390(10096):747-59.

48. Bates ER, Topol EJ. Limitations of fibrinolytic therapy for acute myocardial infarction complicated by congestive heart failure and cardiogenic shock. J Am Coll Cardiol. 1991;18:1077-84.

49. Davies CH, Ormerod OJ. Failed coronary thrombolysis. Lancet. 1998;351:1191-6.

50. Simes RJ, Topol EJ, Holmes DR Jr, et al. Link between the angiographic substudy and mortality outcomes in a large randomized trial of myocardial reperfusion. Importance of early and complete infarct artery reperfusion. GUSTO-I Investigators. Circulation. 1995;91:1923-8.

51. Burjonroppa SC, Varosy PD, Rao SV, et al. Survival of patients undergoing rescue percutaneous coronary intervention: development and validation of a predictive tool. J Am Coll Cardiol Intv. 2011;4:42-50.

52. AM L, Topol EJ. Illusion of reperfusion. Does anyone achieve optimal reperfusion during acute myocardial infarction? Circulation. 1993;88(3):1361-74.

53. Sabatine MS, Cannon CP, Gibson CM, López-Sendón JL, Montalescot G, Theroux P, Claeys MJ, Cools F, Hill KA, Skene AM, McCabe CH, Braunwald E, CLARITY-TIMI 28 Investigators. Addition of clopidogrel to aspirin and fibrinolytic therapy for myocardial infarction with ST-segment elevation. N Engl J Med. 2005;352(12):1179-89.

54. Gershlick AH, Stephens-Lloyd A, Hughes S, Abrams KR, Stevens SE, Uren NG, de Belder A, Davis J, Pitt M, Banning A, Baumbach A, Shiu MF, Schofield P, Dawkins KD, Henderson RA, 
Oldroyd KG, Wilcox R, REACT Trial Investigators. Rescue angioplasty after failed fibrinolytic therapy for acute myocardial infarction. N Engl J Med. 2005;353(26):2758-68.

55. Sutton AG, Campbell PG, Graham R, Price DJ, Gray JC, Grech ED, Hall JA, Harcombe AA, Wright RA, Smith RH, Murphy JJ, Shyam-Sundar A, Stewart MJ, Davies A, Linker NJ, de Belder MA. A randomized trial of rescue angioplasty versus a conservative approach for failed fibrinolysis in ST-segment elevation myocardial infarction: the Middlesbrough Early Revascularization to Limit INfarction (MERLIN) trial. J Am Coll Cardiol. 2004;44(2):287-96.

56. Patel TN, Bavry AA, Kumbhani DJ, Ellis SG. A meta-analysis of randomized trials of rescue percutaneous coronary intervention after failed fibrinolysis. Am J Cardiol. 2006;97(12):1685-90.

57. Wijeysundera HC, Vijayaraghavan R, Nallamothu BK, Foody JM, Krumholz HM, Phillips CO, Kashani A, You JJ, Tu JV, Ko DT. Rescue angioplasty or repeat fibrinolysis after failed fibrinolytic therapy for ST-segment myocardial infarction: a meta-analysis of randomized trials. J Am Coll Cardiol. 2007;49(4):422-30.

58. Assessment of the Safety and Efficacy of a New Treatment Strategy with Percutaneous Coronary Intervention (ASSENT-4 PCI) investigators. Primary versus tenecteplase-facilitated percutaneous coronary intervention in patients with ST-segment elevation acute myocardial infarction (ASSENT-4 PCI): randomised trial. Lancet. 2006;367:569-78.

59. Ellis SG, Tendera M, de Belder MA, FINESSE Investigators. Facilitated PCI in patients with ST-elevation myocardial infarction. N Engl J Med. 2008;358:2205-17.

60. Keeley EC, Boura JA, Grines CL. Comparison of primary and facilitated percutaneous coronary interventions for ST-elevation myocardial infarction: quantitative review of randomised trials. Lancet. 2006;367(9523):1656.

61. SA C, Cannon CP, Ault KA, Antman EM, Van de Werf F, Adgey AA, Gibson CM, Giugliano RP, Mascelli MA, Scherer J, Barnathan ES, Braunwald E, Kleiman NS. High levels of platelet inhibition with abciximab despite heightened platelet activation and aggregation during thrombolysis for acute myocardial infarction: results from TIMI (thrombolysis in myocardial infarction) 14. Circulation. 2000;101(23):2690-5.

62. Ross AM, Huber K, Zeymer U, et al. The impact of place of enrollment and delay to reperfusion on 90-day post-infarction mortality in the ASSENT-4 PCI trial: assessment of the safety and efficacy of a new treatment strategy with percutaneous coronary intervention. J Am Coll Cardiol Intv. 2009;2:925-30.

63. Herrmann HC, Lu J, Brodie BR, et al. Benefit of facilitated percutaneous coronary intervention in high-risk ST-segment elevation myocardial infarction patients presenting to nonpercutaneous coronary intervention hospitals. J Am Coll Cardiol Intv. 2009;2:917-24.

64. Bøhmer E, Hoffmann P, Abdelnoor M, et al. Efficacy and safety of immediate angioplasty versus ischemia-guided management after thrombolysis in acute myocardial infarction in areas with very long transfer distances results of the NORDISTEMI (NORwegian study on DIstrict treatment of ST-elevation myocardial infarction). J Am Coll Cardiol. 2010;55:102-10.

65. Le May MR, Wells GA, Labinaz M, et al. Combined angioplasty and pharmacological intervention versus thrombolysis alone in acute myocardial infarction (CAPITAL AMI study). J Am Coll Cardiol. 2005;46:417-24.

66. Scheller B, Hennen B, Hammer B, et al. Beneficial effects of immediate stenting after thrombolysis in acute myocardial infarction. J Am Coll Cardiol. 2003;42:634-41.

67. Di Mario C, Dudek D, Piscione F, et al. Immediate angioplasty versus standard therapy with rescue angioplasty after thrombolysis in the combined Abciximab Reteplase stent study in acute myocardial infarction (CARESS-in-AMI): an open, prospective, randomised, multicenter trial. Lancet. 2008;371:559-68.

68. Danchin N, Coste P, Ferrières J, et al. Comparison of thrombolysis followed by broad use of percutaneous coronary intervention with primary percutaneous coronary intervention for ST-segment-elevation acute myocardial infarction: data from the French registry on acute ST-elevation myocardial infarction (FAST-MI). Circulation. 2008;118:268-76. 
69. Cantor WJ, Brunet F, Ziegler CP, et al. Immediate angioplasty after thrombolysis: a systematic review. CMAJ. 2005;173(12):1473-81.

70. Armstrong PW. A comparison of pharmacologic therapy with/without timely coronary intervention vs. primary percutaneous intervention early after ST-elevation myocardial infarction: the WEST (which early ST-elevation myocardial infarction therapy) study. Eur Heart J. 2006;27:1530-8.

71. Cantor WJ, Fitchett D, Borgundvaag B, et al. Routine early angioplasty after fibrinolysis for acute myocardial infarction. N Engl J Med. 2009;360:2705-18.

72. Borgia F, Goodman SG, Halvorsen S, et al. Early routine percutaneous coronary intervention after fibrinolysis vs. standard therapy in ST segment elevation myocardial infarction: a metaanalysis. Eur Heart J. 2010;31:2156-69.

73. Larson DM, Duval S, Sharkey SW, et al. Safety and efficacy of a pharmaco-invasive reperfusion strategy in rural ST-elevation myocardial infarction patients with expected delays due to long-distance transfers. Eur Heart J. 2012;33:1232-40.

74. Danchin N, Coste P, Ferrières J, Steg PG, Cottin Y, Blanchard D, Belle L, Ritz B, Kirkorian G, Angioi M, Sans P, Charbonnier B, Eltchaninoff H, Guéret P, Khalife K, Asseman P, Puel J, Goldstein P, Cambou JP, Simon T, FAST-MI Investigators. Comparison of thrombolysis followed by broad use of percutaneous coronary intervention with primary percutaneous coronary intervention for ST-segment-elevation acute myocardial infarction: data from the french registry on acute ST-elevation myocardial infarction (FAST-MI). Circulation. 2008;118(3):268-76.

75. Armstrong PW, Gershlick AH, Goldstein P, et al. Fibrinolysis or primary PCI in ST-segment elevation myocardial infarction. N Engl J Med. 2013;368(15):1379-87.

76. Wallentin L, Becker RC, Budaj A, et al. Ticagrelor versus clopidogrel in patients with acute coronary syndromes. N Engl J Med. 2009;361(11):1045-57.

77. Wiviott SD, Braunwald E, McCabe CH, TRITON-TIMI 38 Investigators, et al. Prasugrel versus clopidogrel in patients with acute coronary syndromes. N Engl J Med. 2007;357(20):2001-15.

78. Bhatt DL, Stone GW, Mahaffey KW, et al. Effect of platelet inhibition with cangrelor during PCI on ischemic events. N Engl J Med. 2013;368(14):1303-13.

79. Madan M, Halvorsen S, Di Mario C, et al. Relationship between time to invasive assessment and clinical outcomes of patients undergoing an early invasive strategy after fibrinolysis for ST-segment elevation myocardial infarction: a patient-level analysis of the randomized early routine invasive clinical trials. J Am Coll Cardiol Interv. 2015;8:166-74.

Open Access This chapter is licensed under the terms of the Creative Commons Attribution 4.0 International License (http://creativecommons.org/licenses/by/4.0/), which permits use, sharing, adaptation, distribution and reproduction in any medium or format, as long as you give appropriate credit to the original author(s) and the source, provide a link to the Creative Commons license and indicate if changes were made.

The images or other third party material in this chapter are included in the chapter's Creative Commons license, unless indicated otherwise in a credit line to the material. If material is not included in the chapter's Creative Commons license and your intended use is not permitted by statutory regulation or exceeds the permitted use, you will need to obtain permission directly from the copyright holder.

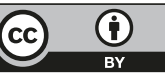

